\title{
Does Sexism Affect Thai Women's Psychological and Behavioural Responses? The Stereotype Threat-Buffering Effect of Mindfulness
}

\author{
Prapimpa Jarunratanakul and Kamonkan Jinchang \\ Faculty of Psychology, Chulalongkorn University, Bangkok, Thailand
}

\begin{abstract}
- ew studies have examined the linkage of perceived sexism with stereotype threat and psychological F responses in a work setting and moderators that may buffer this negative effect. In Study 1, the relationships among perceived sexism, stereotype threat, and psychological responses were explored among Thai female employees $(N=296)$ in a self-report questionnaire study. The aim of Study 2 was to investigate whether mindfulness can mitigate the disastrous effect of sexism on performance, using an experimental design. In Study 1, the standard error of measurement (SEM) results observed a partial mediation effect of stereotype threat for the sexism-disidentification relationship, and sexism only had a significant direct effect on career aspirations. In Study 2, the interaction effect of sexism $\times$ mindfulness on the female participants' reasoning test scores was significant, indicating that those with mindfulness practice performed better when being exposed to sexist behaviours. The current research provides additional information on understanding the impact of sexism on disengagement and decreased career aspirations among Thai female employees in male-dominated industries. In practice, Thai organisations should be concerned about the impact of sexism on disengagement and the protective factor of performance decrements by encouraging anti-sexist norms and fostering the cultivation of mindfulness through practice.
\end{abstract}

Keywords: sexism, stereotype threat, identity separation, career aspirations, mindfulness

Compared to several decades ago, Thai women have improved their education, skills, and qualifications, which has raised their employment opportunities. However, the persistence of sexism at work and traditional gender stereotyping continues to be a barrier for Thai female employees' career progression in male-dominated industries (Bui \& Permpoonwiwat, 2015). Thai female managers in Hansatit's study (2014) reported having some form of career block and discrimination in their roles as managers and that these perceptions may give rise to a lack of confidence and ambition, which might result in the continued absence of women from senior position levels. Although many people today seem not to hold explicitly sexist beliefs toward women (Swim, Aikin, Hall, \& Hunter, 1995), less intense forms of gender discrimination (e.g., sexist jokes or remarks suggesting that women are less skilled, valued and productive than men) are still held by Thai employers. Thai women still lag behind in employment opportunities in business settings, political participation, and upper management positions (VichitVadakan, Jaturongkachoke, Tansanguanwong, Björkman, \& Stalker, 2006). Thus, the mechanisms that produce the sense of demotivation and disengagement in Thai women in male-dominated areas should be examined. Despite widespread evidence for the detrimental effects of pervasive sexism, very little research has discussed a mechanism through which the experience of sexism can demotivate women's prospects of success in their career in non-Western countries, especially in Thailand. The current study attempts to fill that gap.

Sexism is defined as a prejudicial attitude and discriminatory behaviours based on gender identity. Modern sexist behaviours come in various forms, including overt or blatant sexism and covert or subtle sexism (Swim \& Cohen, 1997). Blatant sexism is obviously harmful and includes the unequal treatment of women that is intentional, visible, and unambiguous (e.g., sexual harassment, gender pay gaps, sexist hiring processes, and

Address for correspondence: Prapimpa Jarunratanakul, Faculty of Psychology, Chulalongkorn University, 7th Fl. Borommaratchachonnanisrisattapat Bldg., Rama 1 Rd.Pathumwan, Bangkok, 10330 Thailand.Email:prapimpa.j@chula.ac.th 
a lack of promotions). However, subtle sexism includes the unequal and unfair treatment of women that is hidden or unnoticed because it is built into cultural and social norms (e.g., sexist remarks, sexist jokes, sexist climates; Benokraitis \& Feagin, 1995; Swim \& Cohen, 1997). As noted by Logel et al. (2009), sexist behaviours in the maledominated domains such as mathematics and engineering can trigger both social identity threat and stereotype threat. Compared to working on tasks in domains that are not relevant to the stereotype, females working in maledominated fields are more likely to face the psychological threat of confirming a negative stereotype (Steele, Spencer, \& Aronson, 2002). Based on theories of social identity (Tajfel \& Turner, 1986) and stereotype threat (Steele \& Aronson, 1995), in a domain in which women are likely to be negatively stereotyped, sexist behaviours can create an atmosphere that devalues women's contributions and performance. Social identity theory proposes that an individual's social identity may be at risk of being devalued in a particular context. Interacting with a sexist man may make women sensitive to cues suggesting that he holds sexist attitudes, and their gendered social identity will be devalued. The mere suggestion of sexism may evoke the concern that they will be the target of unfair treatment or discrimination (Adams, Garcia, Purdie-Vaughns, \& Steele, 2006). Such social identity threat can lead to reduced performance, feelings of distrust, and uncertainty about social belonging (Walton \& Cohen, 2007).

Stereotype threat is a specific form of social identity threat, in which negatively stereotyped group members feel pressure to avoid being judged according to that stereotype and fear that they could confirm it through their performance in that domain (Steele \& Aronson, 1995). The threat of being negatively stereotyped can push women away from success in their career in several ways: it can lead them to performance decrements by increasing anxiety, arousal and negative thoughts; it can disrupt the process of problem-solving and reduce memory capacity and task confidence (Shapiro \& Neuberg, 2007); it can lead them to feel that they do not belong to that domain (Walton \& Cohen, 2007); and it can cause them to steer their interest away from a threating domain and cause them to disengage from a threatening domain (Davies, Spencer, Quinn, \& Gerhardstein, 2002). Prior research has sought to identify the situations that lead to stereotype threat and performance decrements for the stereotyped group. The majority of this research has examined the effects of solo status (Beaton, Tougas, Rinfret, Huard, \& Delisle, 2007), group identity salience (Ambady, Shih, Kim, \& Pittinsky, 2001; Marx \& Goff, 2005), and stereotype salience (Frantz, Cuddy, Burnett, Ray, \& Hart, 2004) on academic performance. Other recent research in this area (Blascovich, Spencer, Quinn, \& Steele, 2001; Marx, Stapel, \& Muller, 2005; von Hippel, Issa, Ma, \& Stokes, 2011) has explored other antecedents (e.g., social comparison with men or women) and the consequences of stereotype threat (e.g., stress, anxiety, identity separation, likelihood of reach- ing career goals, job satisfaction, intention to quit). These findings suggest that stereotype effects can go beyond the scope of performance deficit. In Study 1, we sought to extend the prior findings by examining perceived sexism as the antecedent of stereotype threat and psychological responses (i.e., identity separation and lowered career aspirations) as a consequence in non-Western countries and outside laboratory settings.

However, very little research (e.g., Koch, Konigorski, \& Sieverding, 2014) has investigated the influence of sexism on stereotype threat and behavioural outcomes (e.g., performance in a job application context) and possible protective factors of performance decrements among those experiencing sexism. The experience of sexism and stereotype threat can drain cognitive resources and inhibit the target persons from exercising cognitive control and efficiently directing their attentional resources (Beilock, Rydell, \& McConnell, 2007). As noted by Salmon, Hanneman, and Harwood (2010), mindfulness can facilitate the mode of cognitive attentional resource allocation. The core concept of Eastern mindfulness is the ability to pay attention (Kabat-Zinn, 2003). Many studies (e.g., Chan \& Woollacott, 2007; Jha, Krompinger, \& Baime, 2007) have revealed that mindfulness practice can improve attentional abilities (e.g., selective attention, situational awareness, and attentional flexibility). It can be suggested that mindfulness may be an important protective factor of performance decrements during exposure to a sexist environment. Mindfulness can be considered to be a dispositional trait and state that involves awareness of the present moment with non-judgmental acceptance (Brown, Ryan, \& Creswell, 2007). As our Study 2 aimed to examine whether mindfulness will mitigate the negative effect of sexism, state-mindfulness was manipulated through practice.

\section{Overview of Studies}

In accordance with social identity threat and stereotype threat theories (Steele et al., 2002), sexism can create an environment where women fear being judged through the lens of negative stereotypes. These feelings, known as stereotype threat, can cause women to engage in disidentification (i.e., identity separation and lowered career advancement) and intellectual performance decrements. Mindfulness practice can be used to facilitate performance by combating against the resource-depleting effect of stereotype threat as exposure to stereotype threat can drain working memory resources (e.g., Mrazek, Franklin, Phillips, Baird, \& Schooler, 2013). In Study 1, we hypothesised that the experience of sexism in a male-dominated workplace setting elicits feelings of stereotype threat, which leads to disidentification and lowered career aspiration among Thai female employees. In Study 2, we examined whether mindfulness will combat the detrimental effect of sexism on females' reasoning test performance. To test this hypothesis, we used an experimental design to manipulate sexist cues and state-mindfulness. 


\section{STUDY 1}

\section{Sexism and Stereotype Threat}

As noted by Leary and Baumeister (2000), people are sensitive to how others view them, and this makes social interactions become an important trigger of social identity threat or, more specifically, stereotype threat, among women in the real-world social environment at work. Many studies reveal that women face many forms of prejudice, stereotyping, and discrimination (Leaper \& Brown, 2008; Swim, Hyers, Cohen, \& Ferguson, 2001). The most frequent stereotype toward females is academic sexism, in which male students are assumed to have higher abilities than female students in certain areas such as mathematics, science, technology, and engineering (Stout, Dasgupta, Hunsinger, \& McManus, 2011). Considerable research has identified that sexist behaviours toward women can trigger social identity threat and impair women's performance and advancement, particularly in the domains in which women are negatively stereotyped (Koch et al., 2014; Schmader, Johns, \& Forbes, 2008).

Previous experimental studies (Adams et al., 2006; Koch et al., 2014; Logel et al., 2009) have indicated that behavioural interaction in a sexist manner can elicit stereotype threat and subsequently impair women's intellectual performance. Interacting with sexist men created an implicit stereotype threat that subsequently impaired women's performance in cognitive ability test scores and in job interviews. In Koch et al.'s (2014) simulated job interview study, female participants who were exposed to sexist behaviours exhibited by a male interviewer performed significantly worse on the mathematical test than their female counterparts in the non-sexist condition. Sexist behaviours exhibited by a male job application interviewer in Koch et al.'s (2014) study and male engineering classmates in Logel et al.'s (2009) study were intended to determine whether women experienced decreased working memory capacity and lower math scores under such conditions, respectively. The findings of Adams et al.'s (2006) study was also supportive of the concept of social identity threat and stereotype threat in which a suggestion of sexism in an instruction situation could harm women's logic test performance. Although sexism effects appear to be robust, the specific mechanism by which it can elicit stereotype threat and other psychological responses beyond the scope of performance deficits is still not entirely clear. In an extension of these previous studies on sexism and stereotype threat, the current study hypothesised that stereotype threat would mediate the relationships between sexism and its consequences among a sample of Thai female employees in male-dominated domains.

\section{Disidentification}

In addition to the scope of acute performance deficits, disengagement with the threatening domain is one strategy that may be used by stereotype-threatened people. As noted by Steele (1997), individuals who encounter stereotype threat may respond to the threat by disengaging from the negatively stereotyped group. Women in the workplace might adopt this strategy by clearly separating their work roles from their female roles (Pronin, Steele, \& Ross, 2004). By weakening identification with the negatively stereotyped domain, feelings of self-worth are dependent on neither successes nor failures in the domain (Steele et al., 2002). Separating their female role from the work role allows women to emphasise their role as a skilled worker in the workplace (Pronin et al., 2004). Maintaining a clear distinction between female and work roles enables women employees to prevent their female characteristics from serving as a source of stereotyping at work. There has been limited research (e.g., von Hippel et al., 2011) examining disidentification as an outcome of stereotype threat in work settings. This identity separation is highly important, as it can be associated with negative consequences (e.g., depression, intention to leave a job, and job dissatisfaction) for women who feel that they cannot express their female role while enacting their work role. Another form of disidentification is redirecting or altering their aspirations and career paths. Those women who perceive a stereotypical environment tend to show less interest in participating in that negatively stereotyped domain. In Good, Rattan, and Dweck's (2012) study, women were less likely to express their interest in taking more math classes in the future if they perceived that their college math classes were conveying negative stereotypes about women's math abilities. This threat to their identity as a future mathematician or scientist might affect their achievement and career aspiration. Individuals with higher aspirations to advance within their careers often pursue opportunities for leadership, promotion, training or managing others (O'Brien, 1996), and they persist in their attempts to achieve more senior level positions than those with lower aspiration (Tharenou, 2001). The prior research has revealed that the experience of stereotype threat reduces self-efficacy in stereotype-relevant domains (Aronson \& Inzlicht, 2004), and lowers leadership aspirations (Davies, Spencer, \& Steele, 2005) and career aspirations (von Hippel et al., 2011). These findings suggest that experiencing stereotype threat diminishes confidence in achieving career goals (Steele \& Aronson, 1995). The current study seeks to extend these findings by examining how sexism can elicit stereotype threat and subsequently identity separation and lowered career/leadership aspiration in Thai work contexts.

\section{Method}

\section{Samples and Procedure}

A total of 296 female employees from various maledominant industries in the Bangkok metropolitan area completed the questionnaire, with $44.9 \%$ of the respondents in the age range of 26 to 33. The industries in which most of the respondents worked were the military and police institutions (64.35\%), electronic and information 
and communications technology (ICT; 8.4\%), heavy industries $(5.9 \%)$, construction and real estate $(4.9 \%)$, energy and public utilities (4.5\%); the remaining respondents were employed in other industries (e.g., law and finance). The participating organisations comprised 25\% or fewer women. Their education level was high, with $84.7 \%$ holding an undergraduate degree and higher. The average tenure for women in the organisation was 5.40 years, and the average tenure for women in their current position was 6.03 years. The sample used in this study included predominantly public sector employees (67.9\%) with $32.1 \%$ in the private sector.

After obtaining ethical approval from Research Affairs, Chulalongkorn University, the representatives of the participating organisations were contacted seeking permission regarding the administering of the questionnaire to their female employees. After completion, the respondents posted the questionnaire to the first author with a selfaddressed envelope that was provided. This ensures the anonymity and confidentiality of the responses.

\section{Measures}

The measures of sexism, stereotype threat, identity separation, and career aspiration were translated into the Thai language. The back-translation technique (Brislin, 1986) was used to check the equivalence of the wording in the original and back-translated versions by using three English-Thai bilinguals.

Sexism. The Schedule of Sexist Events (SSE; Klonoff \& Landrine, 1995) consists of four factors: sexist degradation, sexism in distant relationships, sexism in close relationships, and sexist discrimination in the workplace. In this study, only four items of recent sexist events in the workplace subscale $(\alpha=.88)$ were assessed: 'How many times have you been treated unfairly by your employer, boss, or supervision because you are a woman?' and 'How many times were you denied a raised, a promotion, tenure, a good assignment, a job, or other such thing at work that you deserved because you are a woman?' The response was a 6-point Likert scale, ranging from The event has never occurred to you to The event occurs almost all the time (more than $70 \%$ of the time).

Stereotype threat. Stereotype threat was measured with 10 items $(\alpha=.89)$ that were adapted from the stereotype threat scales of Steel and Aronson (1995), Bergeron, Block, and Echtenkamp (2006), and von Hippel et al. (2011), to assess the stereotypes relevant to women in the workplace (e.g., 'Some of my co-workers feel that I have less ability because I am a woman'). The responses were given on a 7 -point Likert scale ranging from $1=$ strongly disagree to 7 = strongly agree.

Identity separation. Women's identity separation $(\alpha=.83)$ was assessed with two items developed by von Hippel et al. (2011): 'I am conflicted between the feminine and work ways of doing things', and 'I feel I am continuously switching between my usual feminine- self and my work-self. The response choice was on a 7-point Likert scale ranging from $1=$ strongly disagree to 7 = strongly agree. Higher scores indicate higher levels of identity separation.

Career aspiration. The career aspiration scale (CAS; Gray \& O'Brien, 2007) consists of two subscales: the Leadership and Achievement Aspiration Scale (eight items, e.g., 'I hope to become a leader in my career field') and the Educational Aspiration Scale (two items, e.g., 'I think I would like to pursue graduate training in my occupational area of interest'). Although the measure of career aspiration developed by Gray and O'Brien (2007) is comprised of two dimensions, the CAS score was computed as a single index, dropping four items of the factor Leadership and Achievement Aspirations because of low reliability and the confirmatory factor analysis (CFA) results indicating a single factor and high cross-loadings for the current sample. This decision is in line with the previous research that has reported very low reliabilities of the Educational Aspiration Scale, and it was suggested that two items of the Leadership and Achievement Aspiration Scale be dropped (e.g., Study 3 in Gray \& O’Brien, 2007). The reliability for the total CAS score of the remaining items was .73. The respondents were asked to indicate how true each statement is for them by using a 5-point response scale (ranging from not at all true of $m e=1$ to very true of $m e=5$ ), with a higher score indicating greater aspiration within their career.

\section{Controls}

Controlling for the effect of organisational types on career aspiration may be important, as the prior research (Rashid \& Rashid, 2012) suggests that career development policies appear to be more prevalent in the private sector than in the public sector. Regarding the possible organisational type effect on career aspiration, the subgroup analyses indicated differences in career aspiration between the two organisation types $(F=4.89, d f=294,162.72, p<.01)$, with those employees in public institutions reporting lower scores on career aspiration $(M=3.46, S D=.66)$ than their counterparts in private institutions $(M=3.77, S D=.76)$. Thus, organisation type was included as a control variable in further analyses. Dummy codes of organisational types $(1=$ public sector, $0=$ private sector $)$ were included into the tested model. As suggested by Fritz and Knippenberg (2017), working tenure might influence leadership aspiration. However, organisational and job tenures had no significant correlation with career aspirations $(r=-.12$ and -.10, ns., respectively) in the current sample. Thus, these two variables were not included as control variables.

\section{Results}

Prior to conducting the analysis, all variables were tested for multivariate outliers and normality. The criterion for multivariate outliers in the present research was a Mahalanobis distance at $p<.001$. The $\chi^{2}$ critical value with degrees of freedom equal to the number of variables (four) 
was 13.28 at $p<.001$ (Tabachnick \& Fidell, 2007). The result of the Mahalanobis distance test $\left(D^{2}\right)$ yielded five multivariate outlying cases. After the outlier deletions, a total of 296 cases were retained for further analyses. The skewness and kurtosis values of each variable fell within an acceptable range.

\section{Measurement Model}

In the current research, the chi-square difference test, fit statistics: $\chi^{2} / d f$, standardised root mean squared residual (SRMR), comparative fit index (CFI), and root mean square error of approximation (RMSEA) and parameter estimates were used for the evaluation of model fit. Although the chi-square value should ideally be nonsignificant, indicating a good fit of the model, the chisquare value is always inflated and statistically significant in large sample sizes (Byrne, 2013). For these reasons, the $\chi^{2} / d f$ ratio was used. A good-fitting model may be indicated when the ratio of the chi-square to the degree of freedom $\left(\chi^{2} / d f\right)$ is less than 2 and values up to 5 are considered acceptable (Jackson, Wall, Martin, \& Davids, 1993).

To determine which factor structure of career aspirations produced the best fit to the present data for the current Thai samples, the fit of two different factor structures was compared. The first was a one-factor model comprising 10 items indicative of one career aspiration factor. The second was a two-factor model including leadership and achievement aspiration as one factor ( 8 items) and educational aspiration as the other ( 2 items). The CFA results for career aspirations revealed that the one-factor model was significantly better than the two-factor model. In the two models, 4 items of leadership and achievement aspiration dimension were dropped due to non-significant parameter estimates. To assess which model had a better fit than others, a chi-square difference $\left(\Delta \chi^{2}\right)$ test was used. The one-factor model with 6 items $\left(\chi^{2}=25.11\right.$, $d f=7, p=.000$, RMSEA $=.094$, SRMR $=.037)$ was significantly better than the two-factor model with 6 items $\left(\chi^{2}=54.63, d f=8, p=.000, \mathrm{RMSEA}=.141, \mathrm{SRMR}=.064\right)$ $\left(\Delta \chi^{2}(d f=1)=19.52, p<.01\right)$. Thus, the one-factor model with 6 items was used for the further analyses.

Sexism was modelled as one latent factor with 4 items as its indicators. Fit of the measurement model was good: $\chi^{2}=3.07, d f=1, p=.080, \mathrm{RMSEA}=.084, \mathrm{SRMR}=.013$.

Stereotype threat was modelled as one latent factor with 10 items as indicators of the latent factor. The model showed a good fit: $\chi^{2}=43.96, d f=30, p=.048$, RMSEA $=.04$, SRMR $=.021$.

Identity separation was a one-factor model with 2 items. As noted by Kline (2010), models with less than four indicators per latent variable tend to fail to converge and error estimates can be unreliable. Therefore, we ran the CFA on identity separation with other criterion variables (i.e., career aspirations), that is, the model with two latent factors (i.e., identity separation and career aspirations), with the items as indicators of the latent factors. The fit
Table 1

Mean, Standard Deviation, and Intercorrelations of the Study Variables $(N=296)$

\begin{tabular}{lllllll}
\hline Variables & $M$ & SD & Sexism & ST & IS & CA \\
\hline Sexism & 1.99 & 1.08 & $(.88)$ & & & \\
ST & 2.33 & .83 & $.66^{* * *}$ & $(.89)$ & & \\
IS & 1.88 & .91 & $.55^{* * *}$ & $.54^{* * *}$ & $(.83)$ & \\
CA & 3.56 & .70 & $-.16^{* *}$ & -.05 & -.09 & $(.73)$ \\
\hline
\end{tabular}

Note: $\mathrm{ST}$ = stereotype threat; $\mathrm{IS}=$ identity separation, $\mathrm{CA}=$ career aspiration. Scale reliabilities are shown on the diagonal within the parenthesis.

${ }^{* *} p<.01,{ }^{* * *} p<.001$ (one-tailed).

of the model was within an acceptable range: $\chi^{2}=20.90$, $d f=14, p=.104$, RMSEA $=.041$, SRMR $=.040$.

In sum, the four CFAs (each of the four study variables) gave us confidence in the construct validity of our four scales, demonstrated for each scale item loaded onto one factor.

\section{Descriptive Statistics and Structural Model}

Table 1 presents the means, standard deviations, and intercorrelations of the measures. The scale reliabilities are displayed on the diagonal, ranging from .73 to .89. The correlations between all variables were in the expected direction. Perceived sexism had a significant correlation with stereotype threat, and the two criteria variables (i.e., identity separation and career aspiration).

To test the structural model, item parcels were created to reflect latent variables. This approach allows us to estimate fewer parameters and obtain a more parsimonious and stable model (Little, Cunningham, Shahar, \& Widaman, 2002). The model consists of five latent variables with single indicators. The measurement error variance for single-item indicators of all latent variables, except organisational type dummy variable, was fixed at a value equal to 1 -reliability $\times$ variance of the observed score (Schumacker \& Lomax, 2004). As organisational type was not a scale and does not have any estimate of reliability, the error variance of a single item for organisational type was fixed at a value equal to zero (assuming perfect reliability in the single item; Kelloway, 1998). To examine the mediation model, structural equation modelling (SEM) was employed using LISREL 8.72. We compared three models: the main effect model with no mediation paths, the full mediation model, and the partial mediation model (hypothesised model). The results showed the hypothesised model had significant better fit indices $\left(\Delta \chi_{(1)}^{2}=5.513\right.$, $p<.05)$ than the full mediation model $\left(\chi^{2}=13.92\right.$, $d f=4, p=.007$, RMSEA $=.092)$. Although the fit indices indicated satisfactory overall goodness-of-fit for the main effect model, $\chi^{2}=1.77, d f=2, p=.41, \mathrm{CFI}=1.000$, SRMR $=0.19$, RMSEA $=.000[.000 ; .111]$, no significant direct path from sexism to career aspiration was found $(\beta=-.13, n s)$, and sexism was significantly related to identity separation $(\beta=.67, p<.001)$. The hypothesised model fit well to the observed data, $\chi^{2}=8.407, d f=3, p=.04$, $\mathrm{CFI}=.985, \mathrm{SRMR}=.03, \mathrm{RMSEA}=.07[.0162 ; .143]$. After 


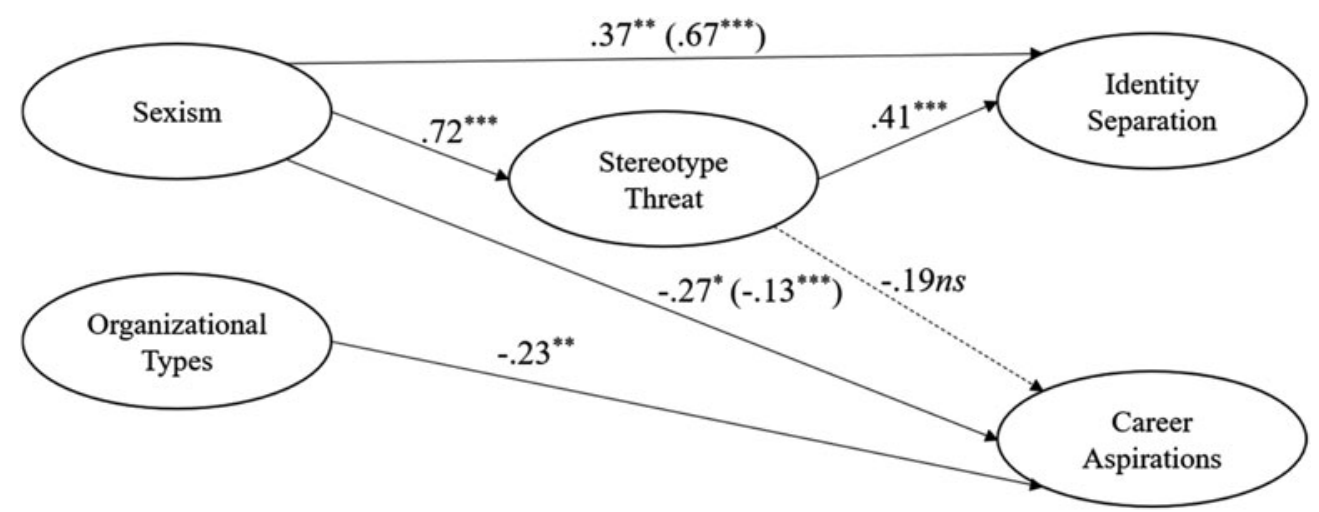

\section{Figure 1}

Standardised path coefficients for the relations between sexism, stereotype threat, and criterion variables (identity separation and career aspiration). The coefficient in the parenthesis represents the direct effect without the mediator in the model.

Note: ${ }^{*} p<.05,{ }^{* *} p<.01,{ }^{* * *} p<.001$

including stereotype threat, the path coefficients from the predictor (sexism) to mediator (stereotype threat) and from the mediator to criterion (identity separation) were significant. The standardised path coefficients for the partial mediation model are presented in Figure 1.

Perceived sexism had a positive relationship with stereotype type threat $(\beta=.72, p<.001)$ and career aspirations $(\beta=-.27, p<.05)$. As expected, stereotype threat was positively related to identity separation $(\beta=.37, p<.01)$. These suggest that the precondition for mediation testing was met for the relationships among sexism, stereotype threat, and identity separation. The indirect effects of sexism on identity separation via stereotype threat was significant $(\beta=.30, p<.001)$. The standardised total effects of sexism on the criterion variable were $.67, p<.001$. These results were supportive of the hypothesised mediation model for identity separation. However, a significant relationship between stereotype threat and career aspiration was not observed. Due to no significant direct path from stereotype threat to career aspiration, the mediating effect was not found for career aspirations. Sexism explained $53 \%$ of the variance in stereotype threat, and $53 \%$ of the variance in identity separation. Sexism, organisational type, and stereotype threat altogether explained $11 \%$ of the variance in career aspiration. As expected, the dummy variable of organisational type that represents public organisations had a significant path with career aspirations $(\beta=-.23, p<.01)$. These indicated that those in the public organisations had a significantly lower score on career aspiration than those in the private organisations.

In short, the results were supportive of the partial mediating role of stereotype threat in the sexism-identity separation link, whereas no support was found for the sexism-career aspiration link. Sexism had a significant direct effect on career aspirations.

\section{Discussion}

Our hypothesis was that the experience of sexism would elicit stereotype threat and consequently lead to identity separation and career aspiration. The overall results were partially supportive of this hypothesis and provide several important implications for sexism research. First, the results of the current study revealed a partial mediating role of stereotype threat in the relationship between sexism and identity separation. Consistent with the concept of stereotype threat theory, exposure to sexism at work can invoke feelings of stereotype threat and cause females to separate their female identity from their work identity to keep their self-esteem intact. This indicates that the detrimental effect of sexism on identity separation was pronounced in a sample of Thai female employees. Those exposed to sexism feel afraid of being judged through the lens of negative stereotype and feel that their female identity cannot be displayed while enacting their work identity (Settles, 2004). Although the mediating role of stereotype threat was supported for the sexism-identity separation link, there was the absence of a relationship between stereotype threat and career aspirations. This is in line with Von Hippel et al.'s study (2011), in which the feeling of stereotype threat had no impact on reducing female employees' career aspirations. Their study suggests that rather than reducing aspirations, female employees reduced their confidence in reaching their career goals.

Another possible reason for the absence of the stereotype threat-career aspiration relationship could result from the use of one summation score of the CAS in this study. The 8-CAS items reflect mainly the two aspects of career aspirations: educational and leadership aspiration. Due to low reliability for the Educational Aspiration Subscale and high cross-loadings, the CAS was computed as a single overall score. One reason for the low reliability is perhaps the low number of items (two items) for the Educational Aspirations. Although Gray and O'Brien (2007) suggested that the CAS may not be components of a single construct, those two items on the Educational Aspiration Subscale loaded onto the Leadership Aspiration dimension in the current study. The 8-item CAS only captures women's desire to become a leader and their interest in 
continued education within their careers; however, it still cannot assess the level of achievement aspirations. Von Hippel's (2011) study also failed to detect the stereotype threat-career aspiration relationship perhaps due to the use of a single item to assess occupational aspirations. As noted by Fassinger (1990), operationalising career choices with single-dimension items might not address the degree of achievement to which women aspire within their career. During the data collection period, the revised version of the 24-items CASR of Kim, O'Brien, and Kim (2016), with three subscales assessing achievement, leadership and educational aspirations, was not available. Future research should further examine this scale validation and its relationship to sexism and stereotype threat among a sample of Thai female employees.

Nevertheless, the results of this study revealed that exposure to sexism at work had significant direct effect on career aspirations. This is in line with Bradley-Geist, Rivera, and Geringer's (2015) experimental study, which found that merely observing or interacting with a male interviewer's sexist behaviours toward female job applicants can deteriorate career aspiration in female participants. The suggestion of sexism can create a threat in the air (Steele, 1997), make the situation less comfortable for the target persons (Hyde \& Kling, 2001), and may be sufficient to produce less positive interaction (Brown \& Dobbins, 2004). This may lead women to avoid interacting with their supervisors and have lowered career aspiration.

More interestingly, organisation type had a significant direct path to career aspiration. The results of this study indicated that public sector employees had a significantly lower score on career aspiration compared with those in the private sector. This is consistent with the previous research (Rashid \& Rashid, 2012) suggesting that public sector employees tend to value and be motivated by career advancement opportunities less than their private sector counterparts. As noted by Moore (1979), career development policies appear to be more prevalent in the private sector than in the public sector. According to Fagenson (1990), individual, organisational and societal factors simultaneously have an impact on women's career advancement. Women may create barriers to their own career advancement by demonstrating poor skills and competencies, and low commitment to work. At the organisational level, discriminatory organisational culture and human resource practices were perceived as barriers to career advancement among Thai female executives (Napasri \& Yukongdi, 2015). Regarding societal pressures, cultural norms that have restrictions based on gender may also act as barriers. The future research on stereotype threat and career aspiration should take individual, organisational and societal barriers into account.

In sum, Study 1 suggests that experiencing sexist behaviours is associated with greater feelings of stereotype threat and that stereotype threat in turn affects two forms of disidentification (identity separation and lowered career aspirations). Despite these findings indicating the negative impact of sexism on females' advancement in the applied settings, the use of a correlational design does not provide the establishment of causality. The goal of Study 2 was to demonstrate the effect of sexism on females' objective performance in a reasoning test and the use of mindfulness practice to reduce this disastrous influence of sexism by using an experimental approach.

\section{STUDY 2}

The existing studies (Koch et al., 2014; Logel et al., 2009) have shown that exposure to sexist behaviours can induce feelings of stereotype threat and impair women's intellectual performance. These previous studies involve the activation of gender stereotypes, in which individuals are aware of relevant sexist cues. Based on the stereotype threat framework of Steele et al. (2002), stigmatised group members may confront performance decrements in situations where the stereotype is evoked and the individuals are conscious of the fact that their behaviours may confirm negative views of a group to which they belong. The feeling of stereotype threat may negatively affect performance through mechanisms such as increased anxiety, reduced working memory capacity and cognitive resources (Quinn \& Spencer, 2001). Stigmatised group members suffered decreased performance only on particular tasks for which working memory is required, such as math problems (Beilock et al., 2007), language processing (e.g., Daneman \& Carpenter, 1980), and reasoning tests (Su" $ß$, Oberauer, Wilhelm, \& Schulze, 2002).

As proposed by Roeser and Pinela (2014), and Weger, Hooper, Meier, and Hopthrow (2011), mindfulness is a potential way to decrease the detrimental effect of stereotype threat. Mindfulness is a state-trait in which individuals experience their environment by paying attention in the present moment with an unbiased and non-judgemental way (Brown et al., 2007). While stereotype threat drains the cognitive resources necessary for task performance (Beilock et al., 2007), mindfulness practice has been used to modulate working memory capacity and direct attentional resources to a target (e.g., Jha et al., 2007). This can reverse the effect of stereotype threat on decreased performance. In an extension of Weger et al.'s (2011) study, our Study 2 additionally used sexist behaviours by a male confederate to activate stereotype threat in which female participants are aware of relevant cues of sexism. This is in contrast with the previous study in which they activated stereotype threat by informing the participants that the test is about assessing gender differences in maths. Compared to Weger et al.'s study (which used a 5-minute audio file providing instruction on how to practise mindfulness while eating two raisins), this study allowed female participants in the sexist condition to have longer periods of mindfulness practices ( 5 minutes for the confederate's explanation on the definition of mindfulness and demonstration on how to practise mindfulness with a raisin task and another 5 minutes to practise the task on their own). 
We expected that those female participants in the sexist condition after practising mindfulness would have a higher score on a reasoning test than those with no mindfulness practice.

Additionally, we conducted a mixed-gender group experiment under conditions that resemble authentic workshop activity to create a sexist environment and activate more intense gender stereotypes (rather than merely presenting cues such that women might underperform in a cognitive task).

\section{Methods}

\section{Sample and Design}

The participants were Thai female undergraduate students recruited from psychology courses at three universities in the Bangkok metropolitan areas $(N=160)$ and given course credits for their participation. This study was a randomised experiment with four conditions: Group $1-$ sexist cues + mindfulness practice $(n=40)$; Group $2-$ sexist cues + non- mindfulness practice $(n=40)$; Group 3 - non-sexist cues + mindfulness practice $(n=40)$; and Group 4 - non-sexist cues + non- mindfulness practice $(n=40)$. The participants were randomly assigned to one of these four conditions in a 2 (sexist cues vs. non-sexist cues) $\times 2$ (mindfulness practice group vs. control group) between subjects design.

\section{Experimental Procedures}

During the sample recruitment weeks, those undergraduate students who registered in psychology courses at three universities were all invited to participate in this study. They were initially informed that this study would offer them a 'Mindfulness and Positive Work Psychology Workshop'. A total of $230(160=$ females and $70=$ males $)$ agreed to participate in the study. Data collection occurred in an experimental laboratory. The male participants were recruited to allow us to induce the experience of sexism around gender and reasoning test performance among the female participants. However, the data obtained from the male participants were not used for further analysis.

In the Sexist cues + Mindfulness condition, the participants were informed by a male confederate that prior to attending this workshop, female participants were required to take a reasoning ability test and that their scores obtained from the test would be used to form a mixedgender group for the workshop activities, to place them in the most appropriate group based on their reasoning ability. However, the confederate informed the participants that males were not required to complete the test due to their previous academic records that showed the outperformance of men in math and reasoning ability tests. This situation indicates behavioural interaction in a sexist manner that induces a feeling of stereotype threat. After the completion of the survey of stereotype threat for the manipulation check, a confederate gave both female and male participants in this condition a 5-minute demonstration on mindfulness practice using a raisin task and another 5 minutes for practising on their own. Then, the participants were asked to fill out a state-mindfulness survey for the manipulation check. Lastly, the female participants were asked to complete 15 multiple-choice reasoning test questions within 15 minutes before being debriefed.

In the sexist cues + non-mindfulness group, the participants received the same treatment as those in the sexist cues + mindfulness condition, except for mindfulness practice. However, in the non-sexist cues + mindfulness condition, both the male and female participants were informed that they had to complete the reasoning test and were not exposed to sexist cues, followed by filling out a stereotype threat survey and mindfulness practice before completing the test. Those in the non-sexist cues and nonmindfulness group followed the same instructions as the non-sexist group but received no additional manipulation of mindfulness before beginning the test.

\section{Experimental Manipulations}

Our stereotype threat and mindfulness manipulations had the desired effect. The female participants in the sexism condition $(n=80), M=2.47, S D=.61$, reported higher scores on stereotype threat than those in the nonsexist cues condition $(n=80), M=2.17, S D=.40, F(1$, $156)=14.31, p<.001$. In the mindfulness group, the female participants had significant higher scores on mindfulness, $M=4.13, S D=.53$, than their counterparts in the non-mindfulness group, $M=3.32, S D=.70, F(1$, 156) $=72.77, p<.001$.

\section{Materials}

Reasoning ability test. The participants were given 15 minutes to complete 15 items of a reasoning ability test that was taken from Raven's Advanced Progressive Matrices (APM; Raven, Raven, \& Court, 1998). The APM is a test of non-verbal or abstract reasoning ability that was constructed as a more difficult version of the test designed for older adolescents and adults. The previous studies have indicated gender differences in both the Standard and Advanced Progressive Matrices (Lynn \& Irwing, 2004), and they found that males had the advantage from age 15 to older age. Mackintosh and Bennet (2005) also found that males did better than females on some items requiring addition/subtraction or the distribution of two rules to solve the problem. From item analyses on APM SET II, we selected 15 out of 36 items with no gender differences from the scores obtained from 361 Thai college students (87 males and 274 females) to measure reasoning ability in this study.

Stereotype threat measure. To assess whether the sexist cues had the desired effect, five items of the gender stereotype threat $(\alpha=.76)$ were employed for a manipulation check. The measure was adapted from Study 1 to assess the negative stereotypes of women in a cognitive ability test (e.g., 'Some people feel I have less cognitive ability because 
Table 2

Two-Way ANOVA Summary: A Score for Reasoning Ability Test

\begin{tabular}{lrrrrl}
\hline Source & \multicolumn{1}{c}{ SS } & $d f$ & MS & \multicolumn{1}{l}{ F } & $\begin{array}{l}\text { Partial eta } \\
\text { squared }\end{array}$ \\
\hline Sexist cues & 100.806 & 1 & 100.806 & $29.853^{* * *}$ & .161 \\
Mindfulness & 117.306 & 1 & 117.306 & $34.739^{* * *}$ & .182 \\
Sexist cues $\times$ & 13.806 & 1 & 13.806 & $4.089^{*}$ & .026 \\
$\quad$ Mindfulness & & & & & \\
Error & 526.775 & 156 & 3.377 & &
\end{tabular}

Note: $\mathrm{SS}=$ sum of squares; $\mathrm{MS}=$ mean square.

${ }^{*} p<.05,{ }^{* * *} p<.001$.

of my gender'). Three out of eight items used in Study 1 were excluded as they were not applicable for the context of Study 2. The responses were given on a 5-point Likert scale ranging from 1 = strongly disagree to 5 = strongly agree.

Mindfulness practice. The raisin mindfulness practice was employed to induce the state of mindfulness. The raisin mindfulness practice was an adapted version of the mindful raisin-eating task used at the beginning of the Mindful Attention-Based Stress Reduction program (MBSR; Kabat-Zinn, 2003), which has been used in many previous experimental studies (e.g., Hong, Lishner, \& Han, 2014; Weger et al., 2011). As this approach is appropriate for beginning mindfulness practitioners, the raisin task was employed in this study. This exercise encouraged the participants to bring their awareness to the present moment by regulating their attention to their current activity. Before the mindfulness practice, the participants in the mindfulness group would learn about the concept of mindfulness, including the procedure to practise mindfulness by eating raisins for 5 minutes. Next, the participant was given 3-4 raisins to practise mindfulness on their own for 5 minutes.

The Mindful Attention Awareness Scale (MAAS) - State. The MAAS - State (Brown \& Ryan, 2003) was used as a manipulation check for the mindfulness state of the participants in the mindfulness group. The participants were asked to complete five items of the MAAS - State ( $\alpha=.75$; e.g., 'I was finding it difficult to stay focused on what was happening.') after the raisin-eating exercise. The responses described the degree to which the participants experienced each item ranging from 0 (not at all) to 4 (very much). Due to low item-total correlation, one out of five items was dropped.

\section{Results}

As predicted, a two-way ANOVA (sexist cues versus nonsexist cues $\times$ mindfulness vs. control group) on the female participants' reasoning test scores revealed a significant two-way interaction, $F(1,156)=4.089, p<.05$, $\eta_{p}{ }^{2}=.026$, such that when experiencing sexist behaviours, those female participants performed significantly better on the reasoning ability test in the mindfulness condition compared to the control condition (see Table 2 for complete ANOVA table and Figure 2 for the interaction effect). The main effects of sexism, $F(1,156)=29.85$, $p<.001, \eta_{p}{ }^{2}=.161$, and mindfulness, $F(1,156)=34.74$, $p<.001, \eta_{p}^{2}=.182$, were significant. Simple effect tests revealed that the participants in the sexist cues condition had a significantly higher score on the reasoning test after engaging in mindfulness practice $(M=12.00)$ than those with no mindfulness practice, $M=9.70), F(1$, $156)=31.332, p<.001, \eta_{p}^{2}=.167$. There was significant difference across conditions when the participants were not exposed to sexist behaviours, $M=13.00$ in the mindfulness group opposed to $M=11.87$ in the nonmindfulness condition, $F(1,156)=7.496, p<.01, \eta_{p}{ }^{2}=$ .046. In the non-mindfulness condition, the participants who experienced sexism $(M=9.70)$ performed significantly worse than those with no exposure to sexism, $M=11.875, F(1,156)=28.019, p<.001, \eta_{p}{ }^{2}=.152$ (see Figure 3).

\section{Discussion}

In this study, the use of sexist behaviours could activate stereotype threat and consequently impair performance on the intellectual task (Davis, Aronson, \& Salinas, 2006). Mindfulness practice appeared to be a successful intervention that reduced the effects of sexist behaviours shown by a male confederate that elicited feelings of stereotype threat and caused the female participants to underperform on a subsequent reasoning test. These findings are in line with the notions that mindfulness can produce positive outcomes such as increased emotion regulation, increased attention regulation, decreased anxiety and increased cognitive processes including working memory and mental flexibility (Hölzel et al., 2011; Moore \& Malinowski, 2009) under stressful events. In contrast with Weger et al. (2011), our study found a significant main effect of sexism on the female participants' reasoning test performance and a significant difference across conditions when the participants experienced non-sexist behaviours between a mindfulness group and a non-mindfulness group. This suggests that the female participants' performance on the reasoning test was affected by the confederate's sexist behaviours. Additionally, a longer period of 10 -minute mindfulness practice in the current study (compared to a 5-minute mindfulness manipulation in the previous study) may enhance attention regulation and provide greater resources to devote to learning, which helps participants transform their mental abilities into academic skills (Zimmerman, 2002).

\section{Limitations and Future Directions}

The limitations of our Study 2 include no establishment of the mechanism leading to decreased performance (e.g., anxiety levels and effort of the threatened individuals, Steele \& Aronson, 1995; physiological indication of mental load, Croizet et al., 2004), and small interaction effects of sexism and mindfulness. Although this study revealed the effect of sexism on reasoning test performance, 


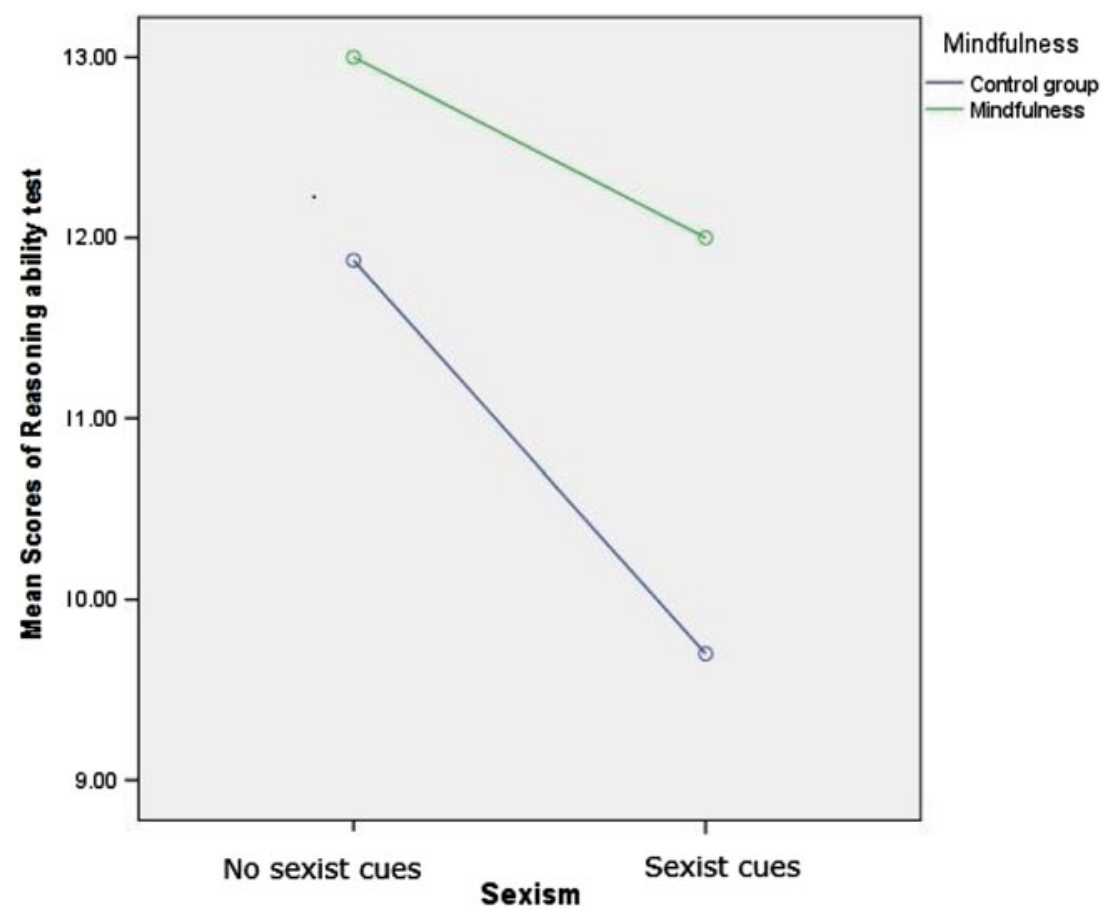

\section{Figure 2}

Sexism $\times$ mindfulness on mean scores of reasoning ability test.

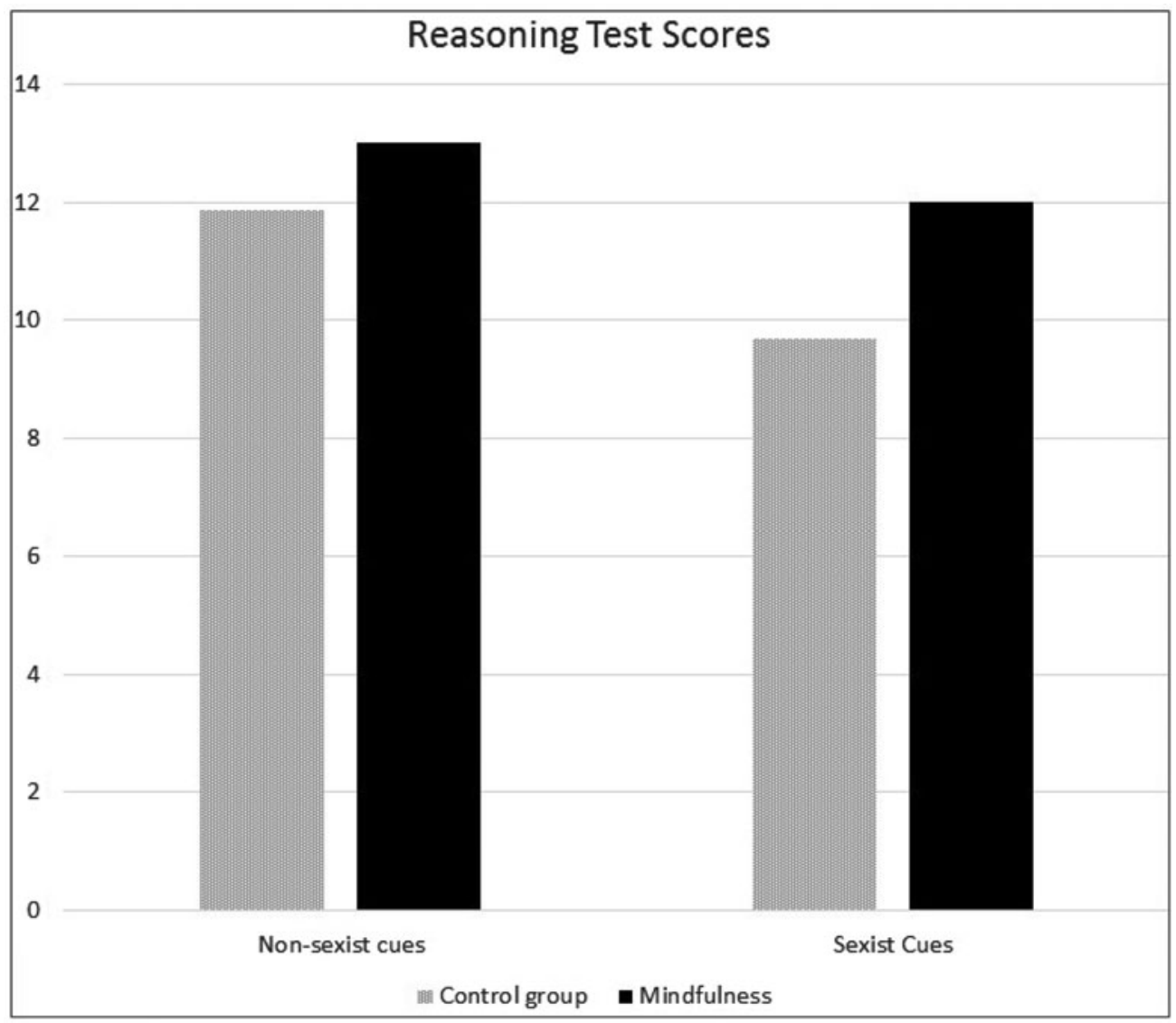

Figure 3

Reasoning test scores as a function of sexist cues and mindfulness. 
the confederate's sexist behaviours may have reduced the female participants' working memory capacity and effort to complete the test, or increased their anxiety levels and thus their reasoning test scores. Mechanisms other than stereotype threat and leading to performance deficit should be explored in future studies. Larger interaction effects should be expected if future studies design the simulation of sexist situations (e.g., group placement for a workshop or project participant selection) to be more realistic and adopt other mindfulness techniques for the participants (e.g., mindful breathing meditation and mindful body scan) to buffer the detrimental influence of sexism and stereotype threat. However, in this study, the simulated situation of participant placement into a mixedgendered group for the workshop in the sexist condition expressed discrimination in a way of protecting women from stress (working in the group that may not be suitable for them; Glick \& Fiske, 2001). As most educational and professional settings explicitly forbid gender discrimination, men may not behave in a way such that their actions could be attributed to sexism (Uhlmann \& Cohen, 2005). In addition, the use of undergraduate female students as in the sample of Study 2 may be questioned with regard to the generalisation of the results. However, Bergeron et al.'s study (2006) on the effect of stereotype threat on women's performance found no significant difference on the stereotype threat scale between those who were working full time and those who were non-working students. Future research in this area, particularly in the work settings of male-dominated industries, should use a more heterogeneous population.

\section{Overall Discussion}

This research contributes to our understanding of gender bias in the Thai workplace by exploring the impact of experienced sexism on identity separation, career aspiration, and performance in male-dominated areas. Our findings suggest that perceived sexist behaviours at work directly diminished females' career aspiration due to demotivation and fewer attempts to attain senior or management level positions. A psychological strategy, by simultaneously separating their female identity from their workrelated identity, is adopted to cope with gender identity threat. As this responsive approach causes many adverse consequences, future research should consider strategies to prevent women from the negative effects of stereotype threat, perhaps through self-affirmation training (Sherman \& Cohen, 2002), creating a positive work climate, celebrating the success of women, and providing female role models (Lockwood, 2006). These might promote gender equality and encourage anti-sexist norms within organisations. The effectiveness of mindfulness as an intervention to inoculate against the pressure of being judged or treated based on stereotypes was supported in the current study. Mindfulness can increase the ability to focus attention and effort on tasks. Our recommendations to decrease the detrimental effect of stereotype threat from sexist behaviours in work or intellectual contexts are to encourage a more gender-fair climate (having role models available for both males and females), raise awareness of ambiguous situations in which discrimination may be justified as a means of protecting women from stress or danger, and provide mindfulness training for inoculation against the effects of sexism and stereotype threat on cognitive performance, especially among stigmatised group members. Our study demonstrated that short-term mindfulness induction can be beneficial in settings where attentional cognitive resources are necessary for task performance. Bringing mindfulness (non-biased perceptions) to any stressful situations can facilitate our decision-making by using our awareness rather than 'going on automatic pilot' (which might be primed or influenced by sexist attitudes or behaviours). When negative gender stereotypes are activated, objective self-awareness might lead the target persons to experience automatic comparison (Duval \& Wicklund, 1972), and distracting thoughts may occur during the completion of cognitive tests (Mrazek et al., 2013). Mindfulness might prohibit these automatic cognitive processes and mind distraction. Organisations should promote the cultivation of mindfulness through training or practices to improve cognitive function, which is associated with task performance.

\section{Funding}

This research was supported by the Office of Research Affairs, Chulalongkorn University, for the social development research cluster (Grant Number 858SD).

\section{References}

Adams, G., Garcia, D.M., Purdie-Vaughns, V., \& Steele, C.M. (2006). The detrimental effects of a suggestion of sexism in an instruction situation. Journal of Experimental Social Psychology, 42, 602-615.

Ambady, N., Shih, M., Kim, A., \& Pittinsky, T.L. (2001). Stereotype susceptibility in children: Effects of identity activation on quantitative performance. Psychological Science, 12, 385390.

Aronson, J., \& Inzlicht, M. (2004). The ups and downs of attributional ambiguity: Stereotype vulnerability and the academic self-knowledge of African American college students. Psychological Science, 15, 829-836.

Beaton, A., Tougas, F., Rinfret, N., Huard, N., \& Delisle, M.-N. (2007). Strength in numbers? Women and mathematics. European Journal of Psychology of Education, 22, 291-306.

Beilock, S.L., Rydell, R.J., \& McConnell, A.R. (2007). Stereotype threat and working memory: Mechanisms, alleviation, and spillover. Journal of Experimental Psychology: General, 136, 256-276.

Benokraitis, N.V., \& Feagin, J.R. (1995). Modern sexism: Blatant, subtle, and covert discrimination. Englewood Cliffs, NJ: Prentice Hall. 
Bergeron, D.M., Block, C.J., \& Echtenkamp, A. (2006). Disabling the able: Stereotype threat and women's work performance. Human Performance, 19, 133-158.

Blascovich, J., Spencer, S.J., Quinn, D., \& Steele, C. (2001). African Americans and high blood pressure: The role of stereotype threat. Psychological Science, 12, 225-229.

Bradley-Geist, J.C., Rivera, I., \& Geringer, S.D. (2015). The collateral damage of ambient sexism: Observing sexism impacts bystander self-esteem and career aspirations. Sex Roles, 73, 29-42.

Brislin, R.W. (1986). The wording and translation of research instruments. In W.J. Lonner \& J. Berry (Eds.), Field methods in cross-cultural research )pp. 136-164). Beverly Hills, CA: Sage.

Brown, K.W., \& Ryan, R.M. (2003). The benefits of being present: Mindfulness and its role in psychological well-being. Journal of Personality and Social Psychology, 84, 822-848.

Brown, K.W., Ryan, R.M., \& Creswell, J.D. (2007). Mindfulness: Theoretical foundations and evidence for its salutary effects. Psychological Inquiry, 18, 211-237.

Brown, L.M., \& Dobbins, H. (2004). Students of color and European American students' stigma-relevant perceptions of university instructors. Journal of Social Issues, 60, 157-174.

Bui, M.-T.T., \& Permpoonwiwat, C.K. (2015). Gender wage inequality in Thailand: A sectoral perspective. International Journal of Behavioral Science, 10, 19-36.

Byrne, B.M. (2013). Structural equation modeling with AMOS: Basic concepts, applications, and programming. New York, NY: Routledge.

Chan, D., \& Woollacott, M. (2007). Effects of level of meditation experience on attentional focus: Is the efficiency of executive or orientation networks improved? Journal of Alternative and Complementary Medicine, 13, 651-657.

Croizet, J.-C., Després, G., Gauzins, M.-E., Huguet, P., Leyens, J.-P., \& Méot, A. (2004). Stereotype threat undermines intellectual performance by triggering a disruptive mental load. Personality and Social Psychology Bulletin, 30, 721-731.

Daneman, M., \& Carpenter, P.A. (1980). Individual differences in working memory and reading. Journal of Verbal Learning and Verbal Behavior, 19, 450-466.

Davies, P.G., Spencer, S.J., Quinn, D.M., \& Gerhardstein, R. (2002). Consuming images: How television commercials that elicit stereotype threat can restrain women academically and professionally. Personality and Social Psychology Bulletin, 28, 1615-1628.

Davies, P.G., Spencer, S.J., \& Steele, C.M. (2005). Clearing the air: Identity safety moderates the effects of stereotype threat on women's leadership aspirations. Journal of Personality and Social Psychology, 88, 276-287.

Davis, C., Aronson, J., \& Salinas, M. (2006). Shades of threat: Racial identity as a moderator of stereotype threat. Journal of Black Psychology, 32, 399-417.

Duval, S., \& Wicklund, R.A. (1972). A theory of objective self awareness. New York, NY: Academic Press.

Fagenson, E.A. (1990). Perceived masculine and feminine attributes examined as a function of individuals' sex and level in the organizational power hierarchy: A test of four theoretical perspectives. Journal of Applied Psychology, 75, 204-211.

Fassinger, R.E. (1990). Causal models of career choice in two samples of college women. Journal of Vocational Behavior, $36,225-248$.

Frantz, C.M., Cuddy, A.J.C., Burnett, M., Ray, H., \& Hart, A. (2004). A threat in the computer: The race implicit association test as a stereotype threat experience. Personality and Social Psychology Bulletin, 30, 1611-1624.

Fritz, C., \& van Knippenberg, D. (2017). Gender and leadership aspiration: The impact of organizational identification. Leadership \& Organization Development Journal, 38, 10181037.

Glick, P., \& Fiske, S.T. (2001). An ambivalent alliance: Hostile and benevolent sexism as complementary justifications for gender inequality. American Psychologist, 56, 109-118.

Good, C., Rattan, A., \& Dweck, C.S. (2012). Why do women opt out? Sense of belonging and women's representation in mathematics. Journal of Personality and Social Psychology, 102, 700-717.

Gray, M.P., \& O'Brien, K.M. (2007). Advancing the assessment of women's career choices: The career aspiration scale. Journal of Career Assessment, 15, 317-337.

Hansatit, P. (2014). A study on gender inequality in Thailand: Career experience of Thai female managers (Doctoral dissertation, Southern Cross University, Lismore, Australia).

Hölzel, B.K., Lazar, S.W., Gard, T., Schuman-Olivier, Z., Vago, D.R., \& Ott, U. (2011). How does mindfulness meditation work? Proposing mechanisms of action from a conceptual and neural perspective. Perspectives on Psychological Science, $6,537-559$.

Hong, P.Y., Lishner, D.A., \& Han, K.H. (2014). Mindfulness and eating: An experiment examining the effect of mindful raisin eating on the enjoyment of sampled food. Mindfulness, 5, 80-87.

Hyde, J.S., \& Kling, K.C. (2001). Women, motivation, and achievement. Psychology of Women Quarterly, 25, 364-378.

Jackson, P.R., Wall, T.D., Martin, R., \& Davids, K. (1993). New measures of job control, cognitive demand, and production responsibility. Journal of Applied Psychology, 78, 753762 .

Jha, A.P., Krompinger, J., \& Baime, M.J. (2007). Mindfulness training modifies subsystems of attention. Cognitive, Affective, \& Behavioral Neuroscience, 7, 109-119.

Kabat-Zinn, J. (2003). Mindfulness-based interventions in context: Past, present, and future. Clinical Psychology: Science and Practice, 10, 144-156.

Kelloway, E.K. (1998). Using LISREL for structural equation modeling: A researcher's guide. Thousand Oaks, CA: SAGE Publications.

Kim, Y.H., O’Brien, K.M., \& Kim, H. (2016). Measuring career aspirations across cultures. Journal of Career Assessment, 24, 573-585.

Kline, R.B. (2010). Promise and pitfalls of structural equation modeling in gifted research. In B. Thompson \& R.F. Subotnik (Eds.), Methodologies for conducting research of giftedness 
(pp. 147-169). Washington, DC: American Psychological Association.

Klonoff, E.A., \& Landrine, H. (1995). The schedule of sexist events: A measure of lifetime and recent sexist discrimination in women's lives. Psychology of Women Quarterly, 19, 439472 .

Koch, S.C., Konigorski, S., \& Sieverding, M. (2014). Sexist behavior undermines women's performance in a job application situation. Sex Roles, 70, 79-87.

Leaper, C., \& Brown, C.S. (2008). Perceived experiences with sexism among adolescent girls. Child Development, 79, 685704 .

Leary, M.R., \& Baumeister, R.F. (2000). The nature and function of self-esteem: Sociometer theory. Advances in Experimental Social Psychology, 32, 1-62.

Little, T.D., Cunningham, W.A., Shahar, G., \& Widaman, K.F. (2002). To parcel or not to parcel: Exploring the question, weighing the merits. Structural Equation Modeling: A Multidisciplinary Journal, 9, 151-173.

Lockwood, P. (2006). 'Someone like me can be successful': Do college students need same-gender role models? Psychology of Women Quarterly, 30, 36-46.

Logel, C., Walton, G.M., Spencer, S.J., Iserman, E.C., von Hippel, W., \& Bell, A.E. (2009). Interacting with sexist men triggers social identity threat among female engineers. Journal of Personality and Social Psychology, 96, 1089-1103.

Lynn, R., \& Irwing, P. (2004). Sex differences on the progressive matrices: A meta-analysis. Intelligence, 32, 481-498.

Mackintosh, N.J., \& Bennett, E.S. (2005). What do Raven's Matrices measure? An analysis in terms of sex differences. Intelligence, 33, 663-674.

Marx, D.M., \& Goff, P.A. (2005). Clearing the air: The effect of experimenter race on target's test performance and subjective experience. British Journal of Social Psychology, 44, 645-657.

Marx, D.M., Stapel, D.A., \& Muller, D. (2005). We can do it: The interplay of construal orientation and social comparisons under threat. Journal of Personality and Social Psychology, 88, $432-446$.

Moore, A., \& Malinowski, P. (2009). Meditation, mindfulness and cognitive flexibility. Consciousness and Cognition, 18, $176-186$

Moore, L. (1979). From manpower planning to human resource planning through career development. Personnel, 56, 9-16.

Mrazek, M.D., Franklin, M.S., Phillips, D.T., Baird, B., \& Schooler, J.W. (2013). Mindfulness training improves working memory capacity and GRE performance while reducing mind wandering. Psychological Science, 24, 776-781.

Napasri, T., \& Yukongdi, V. (2015). A study of Thai female executives: Perceived barriers to career advancement. Review of Integrative Business and Economics Research, 4, 108-120.

O'Brien, K.M. (1996). The influence of psychological separation and parental attachment on the career development of adolescent women. Journal of Vocational Behavior, 48, 257-274.

Quinn, D., \& Spencer, S. (2001). The interference of stereotype threat with women's generation of mathematical problemsolving strategies. Journal of Social Issues, 57, 55-71.
Pronin, E., Steele, C.M., \& Ross, L. (2004). Identity bifurcation in response to stereotype threat: Women and mathematics. Journal of Experimental Social Psychology, 40, 152-168.

Rashid, S., \& Rashid, U. (2012). Work motivation differences between public and private sector. American International Journal of Social Science, 1, 24-33.

Raven, J., Raven, J.C., \& Court, J.H. (1998). Manual for Raven's progressive matrices and vocabulary scales. Section 4: The advanced progressive matrices. San Antonio, TX: Harcourt Assessment.

Roeser, R.W., \& Pinela, C. (2014). Mindfulness and compassion training in adolescence: A developmental contemplative science perspective. New Directions for Youth Development, 2014(142), 9-30.

Salmon, P., Hanneman, S., \& Harwood, B. (2010). Associative/dissociative cognitive strategies in sustained physical activity: Literature review and proposal for a mindfulnessbased conceptual model. The Sport Psychologist, 24, 127-156.

Schmader, T., Johns, M., \& Forbes, C. (2008). An integrated process model of stereotype threat effects on performance. Psychological Review, 115, 336-356.

Schumacker, R.E., \& Lomax, R.G. (2004). A beginner's guide to structural equation modeling. New York, NY: Psychology Press.

Settles, I.H. (2004). When multiple identities interfere: The role of identity centrality. Personality and Social Psychology Bulletin, 30, 487-500.

Shapiro, J.R., \& Neuberg, S.L. (2007). From stereotype threat to stereotype threats: Implications of a multi-threat framework for causes, moderators, mediators, consequences, and interventions. Personality and Social Psychology Review, 11, $107-130$.

Sherman, D.K., \& Cohen, G.L. (2002). Accepting threatening information: Self-affirmation and the reduction of defensive biases. Current Directions in Psychological Science, 11, 119123.

Steele, C.M. (1997). A threat in the air: How stereotypes shape intellectual identity and performance. American Psychologist, $52,613-629$.

Steele, C.M., \& Aronson, J. (1995). Stereotype threat and the intellectual test performance of African Americans. Journal of Personality and Social Psychology, 69, 797-811.

Steele, C.M., Spencer, S.J., \& Aronson, J. (2002). Contending with group image: The psychology of stereotype and social identity threat. Advances in Experimental Social Psychology, 34, 379-440.

Stout, J.G., Dasgupta, N., Hunsinger, M., \& McManus, M.A. (2011). STEMing the tide: Using ingroup experts to inoculate women's self-concept in science, technology, engineering, and mathematics )STEM). Journal of Personality and Social Psychology, 100, 255-270.

Süß, H.-M., Oberauer, K., Wittmann, W.W., Wilhelm, O., \& Schulze, R. (2002). Working memory capacity explains reasoning ability and a little bit more. Intelligence, 30, 261-288.

Swim, J.K., Aikin, K.J., Hall, W.S., \& Hunter, B.A. (1995). Sexism and racism: Old-fashioned and modern prejudices. Journal of Personality and Social Psychology, 68, 199-214. 
Swim, J.K., \& Cohen, L.L. (1997). Overt, covert, and subtle sexism. Psychology of Women Quarterly, 21, 103-118.

Swim, J.K., Hyers, L.L., Cohen, L.L., \& Ferguson, M.J. (2001). Everyday sexism: Evidence for its incidence, nature, and psychological impact from three daily diary studies. Journal of Social Issues, 57, 31-53.

Tabachnick, B.G., \& Fidell, L.S. (2007). Using multivariate statistics. Boston, MA: Pearson Education.

Tajfel, H., \& Turner, J.C. (1986). The social identity theory of inter-group behaviour. In S. Worchel \& W.G. Austin (Eds.), Psychology of intergroup relations (pp. 7-24). Chicago, IL: Nelson-Hall.

Tharenou, P. (2001). Going up? Do traits and informal social processes predict advancing in management? Academy of Management Journal, 44, 1005-1017.

Uhlmann, E., \& Cohen, G.L. (2005). Constructed criteria: Redefining merit to justify discrimination. Psychological Science, $16,474-480$.
Vichit-Vadakan, J., Jaturongkachoke, K., Tansanguanwong, P., Björkman, H., \& Stalker, P. (2006). Women's right to a political voice in Thailand. Bangkok, Thailand: United Nations Development Programme.

von Hippel, C., Issa, M., Ma, R., \& Stokes, A. (2011). Stereotype threat: Antecedents and consequences for working women. European Journal of Social Psychology, 41, 151161.

Walton, G.M., \& Cohen, G.L. (2007). A question of belonging: Race, social fit, and achievement. Journal of Personality and Social Psychology, 92, 82-96.

Weger, U.W., Hooper, N., Meier, B.P., \& Hopthrow, T. (2011). Mindful maths: Reducing the impact of stereotype threat through a mindfulness exercise. Consciousness and Cognition, $21,471-475$.

Zimmerman, B.J. (2002). Becoming a self-regulated learner: An overview. Theory into Practice, 41, 6470. 